\title{
Circulating E-selectin levels and insulin resistance are associated with early stages of atherosclerosis in nonfunctional adrenal incidentaloma
}

Tuncay Delibasi', Basak Karbek ${ }^{2}$, Nujen Colak Bozkurt', Evrim Cakir ${ }^{3}$, Askin Gungunes', Ölknur Öztürk Ünsal' ', Muyesser Sayki Aslan', Erman Cakal'

1 Department of Endocrinology and Metabolism, Diskapi Yildirim Beyazit Training and Research Hospital, Ankara, Turkey 2 Department of Endocrinology and Metabolism, Gaziantep Dr. Ersin Arslan Hospital, Gaziantep, Turkey ${ }^{3}$ Department of Endocrinology and Metabolism, Amasya Sabuncuoglu Serefettin Hospital, Amasya, Turkey

\section{Correspondence to:}

Basak Karbek

Milli Egemenlik Bulvarı,

Sanlilar apt., No 51/9

Gaziantep, Turkey

b_karbek@yahoo.com

Received on Apr/1/2015 Accepted on Apr/7/2015

DOI: 10.1590/2359-3997000000053

\begin{abstract}
Objective: To evaluate circulating E-selectin levels in patients with nonfunctional adrenal incidentaloma (NFA) in relation to insulin resistance and early atherosclerosis. Subjects and methods: A total of 40 patients with NFA (mean [SD] age: 55.6 [10.7] years; $70 \%$ were females) and 35 controls (mean [SD] age: 51.5 [8.1] years; $71.4 \%$ were females) selected from age-, gender- and body mass index (BMI)- matched healthy subjects were enrolled. Serum hsCRP, lipid profile, insulin levels and the homeostasis model assessment of insulin resistance (HOMA-IR) were evaluated. High-resolution Bmode ultrasonography was performed. Serum levels of E-selectin were evaluated by enzyme-linked immunosorbent assay. Results: Patients with NFA had significantly higher values for E-selectin (14.9 (4.8) vs. $12.2(4.1) \mathrm{ng} / \mathrm{mL}, \mathrm{p}<0.01)$ and CIMT $(0.6(0.1)$ vs. $0.5(0.1) \mathrm{mm}, \mathrm{p}<0.05)$ than controls. Serum E-selectin levels showed a statistically significant association with $h \mathrm{CRP}(r=0.751, p<0.001)$, HOMA-IR $(r=0.575, p<0.001)$ and CIMT $(r=0.762, p<0.001)$. CIMT (Carotid intima media thickness) was increased in patients with NFA patients with NFA were more insulin resistant than controls and statistically significant relationship was found between size of tumor and HOMA-IR $(r=0.361$, $p<0.001$ ). Conclusion: In conclusion, based on significantly higher values for E-selectin, CIMT and HOMA-IR in patients with NFA than controls along with significant correlation of E-selectin levels to CIMT, HOMA-IR and hs-CRP, our findings seems to indicate an increased risk of early atherosclerosis and impaired endothelial function in NFA patients, particularly in case of insulin resistance. Arch Endocrinol Metab. 2015;59(4):310-7
\end{abstract}

\section{Keywords}

Adrenal incidentaloma; E-selectin; CIMT; atherosclerosis; insulin resistance

\section{INTRODUCTION}

$\mathrm{T}$ he term adrenal incidentaloma (AI) is usually defined as an adrenal mass unexpectedly detected through an imaging procedure performed for reasons unrelated to adrenal dysfunction or suspected dysfunction. The presence of an AI has been associated with an increased incidence of several cardiovascular risk factors including high prevalence of obesity, hypertension, diabetes mellitus, glucose intolerance, and dyslipidemia (1-4). However, despite well-known association of nonfunctional adrenal incidentaloma (NFA) with cardiovascular risk factors, the exact mechanism underlying this relationship has not yet been clarified.

Among patients with non-secreting adrenal masses undergoing surgery for tumor size or growth, an improvement in blood pressure and fasting glucose levels was demonstrated postoperatively, even in the lack of causative hormonal alterations prior to operation (5).
Some authors suggested an association between NFA and mild cortisol overproduction secondary to diseases such as subclinical hypercortisolism or subclinical Cushing syndrome (SCS) (6,7). On the other hand, hyperinsulinemia mediated pathogenesis has been considered by other authors who observed a proliferative effect of insulin on adrenal cancer cells without effect on cortisol synthesis (8).

In contrast to other adhesion molecules such as intercellular adhesion molecule-1 (ICAM-1), vascular cell adhesion molecule-1 (VCAM-1) and P-selectin that are synthesized and released from endothelial cells, as well as from other cells including fibroblasts, smooth muscle cells and platelets, E-selectin is produced specifically by endothelial cells (9). In this regard, E-selectin has been subject to several studies in terms of its relation to carotid atherosclerosis and the risk of coronary heart disease (10-13) given that higher likelihood of E-selection to be 
a specific marker for endothelial cell dysfunction and thereby the development of atherosclerosis than other adhesion molecules (14). Experimental results suggested that E-selectin may influence intimal hyperplasia through the regulation of inflammatory cell infiltration (15). Accordingly, significant associations were shown in most of the clinical studies of patients with coronary disease (11-13). Given that processes that lead to inflammation of vasculature and/or initiation of endothelial dysfunction may contribute to the development of atherosclerosis, positive association of serum levels of E-selectin as well as hsCRP with carotid atherosclerosis was documented, while Eselectin levels were reported to be significantly associated with carotid wall thickening and were strongly associated with the presence of heterogeneous plaque (14).

The present study was designed to evaluate circulating E-selectin levels in patients with apparently NFA in relation insulin resistance (IR) and early atherosclerosis.

\section{SUBJECTS AND METHODS}

\section{Study population}

Of 73 patients referred to our center with the incidental diagnosis of unilateral adrenal mass with typical signs of adenoma (size less than $4 \mathrm{~cm}$, round with smooth margins, homogeneous with relatively low density, loss of signal intensity on fat-saturation sequences of MR) during computed tomography (CT) or nuclear magnetic resonance (MR) scan performed by the same radiologist for the evaluation of unrelated diseases such as urinary infection, renal or biliary colic, or nonspecific abdominal pain, 40 patients with NFA (mean [SD] age: 55.6 [10.7] years; $70 \%$ were females) were included in this prospective study conducted between September 2009 and September 2011 at the Department Endocrinology and Metabolism in Ankara Diskapi Training and Research Hospital. Patients with pheochromocytoma (n: 1 ), adrenal carcinoma (n: 1 ), aldosteronoma (n: 2) or SCS (n: 5) were excluded. Twenty four other patients with adrenal adenoma were excluded because of obesity (n: 4), previous history of diabetes mellitus (n: 11) or coronary artery disease (n: 9). In seven of these patients coexisted more than one exclusion criteria. Control group was selected amongst age-, genderand body mass index (BMI)- matched healthy subjects with normal adrenal imaging $(\mathrm{n}=35$; mean $[\mathrm{SD}]$ age: 51.5 [8.1] years; $71.4 \%$ were females) to be able perform a $1: 1$ case-control analysis.
Having negative findings on screening tests performed to rule out catecholamine, mineralocorticoid as well as glucocorticoid overproduction, lacking symptoms of overt endocrinopathy or any other disease that could interfere with the results were the inclusion criteria. Patients with a past history of acute coronary syndrome, heart failure, pulmonary embolism, stroke, cardiomyopathy and renal disease were excluded from the study, as were patients with diabetes mellitus and obesity. The diagnosis of pheochromocytoma, adrenal carcinoma, aldosteronoma or SCS were the other exclusion criteria to enable the study population to be composed specifically of patients with NFA.

Written informed consent was obtained from each subject following a detailed explanation of the objectives and protocol of the study which was conducted in accordance with the ethical principles stated in the "Declaration of Helsinki" and approved by the institutional ethics committee.

\section{Study parameters}

Data on demographic characteristics (age, gender), vital signs, physical examination, anthropometric measurements (weight, height, body mass index [BMI]), insulin resistance, blood biochemistry (fasting blood glucose, lipid profile, insulin and hsCRP), CIMT and serum levels for E-selectin were collected in each subject in the patient and control groups. Circulating E-selectin levels in patients with apparently NFA were evaluated in comparison to controls and in relation to insulin resistance, hsCRP levels, CIMT and cardiovascular risk factors.

\section{Clinical and biochemical assessments}

Blood pressure was measured using a sphygmomanometer in a quiet room after at least 10 minutes of rest. Evaluation of obesity was based on BMI $(\mathrm{kg} /$ $\mathrm{m}^{2}$ ) values with consideration of obesity in patients with BMI of $>30 \mathrm{~kg} / \mathrm{m}^{2}$. Fasting blood samples were taken in the morning between 8:00 and 11:00. Routine blood chemistry analyses were performed at the central laboratory of clinical chemistry of the hospital. The patients whose fasting blood glucose greater 100 $\mathrm{mg} / \mathrm{dL}$ underwent OGTT. Only patients with normal glucose tolerance were included in the study. Analysis of serum levels for high-density lipoprotein cholesterol (HDL-C), total cholesterol (TC) and triglycerides were performed via spectrophotometric assay (Advia 2400, Siemens Healthcare Diagnostics Inc., Tarrytown USA). Fasting serum insulin levels were measured us- 
ing the chemiluminescent immunoassay method (Advia Centaur XP, Siemens Healthcare Diagnostics Inc., Tarrytown USA). hsCRP levels were determined by a particle-enhanced immunoturbidimetric method.

The estimate of insulin resistance was calculated using the HOMA-IR index with the formula: [HOMA-IR = fasting plasma insulin $(\mathrm{mU} / \mathrm{L}) \times$ fasting plasma glucose $(\mathrm{mmol} / \mathrm{L}) / 22.5]$. Patients with HOMA-IR levels of $\geq$ 2.5 were considered to have insulin resistance.

\section{Endocrine work-up}

None of the patients with NFA showed specific signs and/or symptoms of hormone excess and none were receiving hormonal therapy. All patients underwent the endocrine workup aimed to study the hypothalamic-pituitary-adrenal axis. Serum cortisol, and plasma ACTH were determined in basal condition and measurement of the 24-h excretion of UFC was performed. All patients underwent an overnight 1-mg dexamethasone (DXM) test. The suppression was adequate when morning cortisol reduced $<1.8 \mu \mathrm{g} / \mathrm{dL}$. If inadequate, a two-day low-dose DXM suppression test was performed (2 mg, four times/day, for 2 days). Urinary metanephrine, and normetanephrine excretion to exclude the presence of pheochromocytoma and the upright plasma aldosterone to plasma renin activity ratio to exclude primary aldosteronism were tested. In control subjects, measurement of serum cortisol in the morning, measurement of 24-h UFC excretion and overnight low-dose dexamethasone suppression test were performed. Normal ranges of serum and urinary cortisol and plasma ACTH were determined as previously reported (16) (Table 1).

Table 1. Hormonal data of the patients with incidental adrenal adenoma and control subjects

\begin{tabular}{|c|c|c|c|}
\hline & $\begin{array}{l}\text { Nonfunctional } \\
\text { adrenal } \\
\text { incidentaloma } \\
(n=40)\end{array}$ & $\begin{array}{l}\text { Control } \\
(n=35)\end{array}$ & $\begin{array}{c}\text { Referance } \\
\text { range }\end{array}$ \\
\hline & \multicolumn{2}{|c|}{ Mean (SD) } & \\
\hline Cortisol ( $\mu \mathrm{g} / \mathrm{dL})$ & $13.1(3.4)$ & $12.1(3.0)$ & $5-25$ \\
\hline 1 mg DST ( $\mu \mathrm{g} / \mathrm{dL})$ & $1.9(0.6)$ & $1.6(0.5)$ & $<1.8$ \\
\hline ACTH (pg/mL) & $13.2(5.7)$ & $14.6(6.9)$ & $7-55$ \\
\hline 24 h UFC (nmol/day) & $192.5(44.4)$ & $182.5(56.1)$ & $100-379$ \\
\hline DHEAS ( $\mu \mathrm{g} / \mathrm{dL})$ & $32,4(18.7)$ & $29.3(12.7)$ & $18-295$ \\
\hline ARR & $12.6(5.2)$ & $14.2(4.6)$ & $<20$ \\
\hline 24 h UMN ( $\mu$ g/day) & $155.5(44.6)$ & 175.8 (32.9) & $52-341$ \\
\hline 24 h UNMN ( $\mu g /$ day & 273.2 (55.5) & $242.5(61.2)$ & $88-444$ \\
\hline
\end{tabular}

ACTH: adrenocorticotrophic hormone; DST: dexamethasone suppression test; DHEAS: dehydroepiandrosterone Sulfate; UFC: urinary free cortisol; ARR: aldosteron/renin ratio; UMN: urinary metanephrine; UNMN: urinary normetanephrine.
SCS was defined as an adrenal tumor (usually adeno$\mathrm{ma}$ ) with autonomous cortisol secretion and no overt symptoms of Cushing's syndrome. Diagnostic criteria for SCS based on the 1-mg DST cut-off value of serum cortisol of $>1.8 \mu \mathrm{g} / \mathrm{dL}$. We selected two additional values (basal adrenocorticotropic hormone $(\mathrm{ACTH})<$ $10 \mathrm{pg} / \mathrm{mL}$ and serum cortisol $\geq 5 \mu \mathrm{g} / \mathrm{dL}$ at 23:00 h) from several parameters, because these values showed stronger associations with the results of the 1-mg DST than the other parameters $(17,18)$.

\section{Measurement of serum levels for E-selectin}

Fasting blood samples were taken from the participants and centrifuged. Serum samples were stored frozen at $-80^{\circ} \mathrm{C}$ until the day of analysis. Serum E-selectin level was measured on all samples by commercial ELISA kit (Invitrogen, USA). The microplate in the kit was precoated with anti-E-selectin antibody. E-selectin present in the sample or standard binds to antibodies adsorbed onto microwells. An HRP was added to bind to E-selectin captured by the first antibody. Following incubation and wash step, substrate solution was added to the wells. The reaction was terminated by addition of acid, and absorbance was measured at $450 \mathrm{~nm}$. The analytical range was considered as $0.33-50 \mathrm{ng} / \mathrm{mL}$. The intraassay coefficient of variation was $5.4 \%$.

\section{Measurement of CIMT}

Examination was performed to evaluate early atherosclerosis using a real time B-mode ultrasound imaging unit (Hitachi EUB 7000, Tokyo, Japan) with a $13 \mathrm{MHz}$ linear transducer. Both the left and right carotid arteries were scanned at the level of the bifurcation, and images for IMT measurements were recorded from the far wall in the common carotid artery and the carotid artery bulb. IMT was defined as the distance from the leading edge of the lumen-intima interface to the leading edge of the media-adventitia interface of the far wall. At the position of the thickest part of the wall, a frozen longitudinal image was captured and recorded on videotape. The procedure was repeated four times to achieve four separate images for analysis. All scans and image measurements were carried out by the same investigator, who was blinded to the risk factor status of the participants.

\section{Statistical analysis}

Data were evaluated using the Statistical Package for the Social Sciences (SPSS) software (version 15.0; SPSS Inc., 
Chicago, IL, USA). In testing the difference between groups after testing normality of variables, an independent samples t-test was used to test the difference between two groups if variables were normally distributed, while the Mann-Whitney $U$ test was used if variables were not normally distributed. A one-way analysis of variance (ANOVA) was used to test the difference between more than two groups if variables were normally distributed, while the Kruskal Wallis $\mathrm{H}$ test followed by a Bonferroni correction was used if variables were not normally distributed. Associations between variables were tested using a correlation analysis. Linear regression analysis was performed with the CIMT measurement as the dependent variable while age, BMI, waist/hip ratio, morning cortisol, HOMA-IR, TC, LDL-C, HDL-C, HsCRP and HOMA-IR were the continuous variables selected for the linear regression model. The level of significance was set at 0.05 .

\section{RESULTS}

\section{Demographic and clinical characteristics in patient and control groups}

The mean (SD) adrenal mass size in NFA patients was $3.0(0.7) \mathrm{cm}$. None of the patients showed specific signs and symptoms of hormone excess. None of the patients with NFA underwent adrenalectomy and follow-up with serial CT or MRI and endocrine evaluation was planned.

Patient and control groups were homogenous in terms of demographic characteristics. Mean (SD) levels for serum E-selectin (14.9 [4.8] ng/mL vs. 12.2 (4.1) ng/mL, p < 0.01), HOMA-IR (3.3 [2.9] vs. 2.7 $[1.2] ; \mathrm{p}<0.05)$ and CIMT $(0.6[0.1]$ vs. $0.5[0.1] \mathrm{mm}$, $\mathrm{p}<0.05)$ were significantly higher in patients with NFA when compared with control subjects. The two groups were similar in terms of other clinical characteristics (Table 2).

\section{Correlation of E-selectin levels to demographic and clinical parameters in the overall study population}

Serum levels for E-selectin showed statistically significant correlations with HOMA-IR $(\mathrm{r}=0.575$, $\mathrm{p}$ $<0.001)$, hsCRP $(\mathrm{r}=0.751, \mathrm{p}<0.001)$ and CIMT $(\mathrm{r}=0.762, \mathrm{p}<0.001)$ (Table 2, Figure 1). A significant correlation was also noted with total cholesterol $(\mathrm{r}=$ $0.408, \mathrm{p}<0.001$ ), while no significant correlation of $\mathrm{E}$ selectin levels to age, gender, BMI and other biochemical parameters was determined (Table 3 ).
There were no significant correlations between baseline plasma cortisol, plasma cortisol after $1 \mathrm{mg}$ dexametasone and HOMA index as well as plasma lipoproteins. Statistically significant relationship was found between size of tumor and HOMA-IR $(\mathrm{r}=0.361, \mathrm{p}<$ $0.001)$, CIMT $(r=0.539, \mathrm{p}<0.001)$.

Table 2. Demographic, clinical characteristics and metabolic profile of patients with nonfunctional adrenal incidentaloma and control subjects

\begin{tabular}{lcc}
\hline & $\begin{array}{c}\text { Nonfunctional } \\
\text { adrenal } \\
\text { incidentaloma } \\
\text { (n = 40) }\end{array}$ & Control (n = 35) \\
\hline & Mean (SD) \\
\hline Age (years) & $55.6(10.7)$ & $51.5(8.1)$ \\
Gender & $\mathrm{n}(\%)$ \\
Male & $12(30.0)$ \\
Female & $28(70.0)$ & $10(28.6)$ \\
\hline & Mean (SD) & $25(71.4)$ \\
\hline BMI (kg/m²) & $28.1(2.1)$ \\
Waist/hip ratio & $0.8(0.1)$ & $28.0(1.9)$ \\
\hline & $\mathbf{n ~ ( \% )}$ & $0.9(0.1)$ \\
\hline Hypertension & $6(15.0)$ & $6(17.0)$ \\
\hline & Mean (SD) \\
\hline Total cholesterol (mg/dL) & $185.0(30.3)$ \\
Triglycerides (mg/dL) & $130.1(52.2)$ & $191.3(29.8)$ \\
HDL cholesterol (mg/dL) & $58.3(25.6)$ & $48.2(10.1)$ \\
LDL cholesterol (mg/dL) & $99.4(31.3)$ & $112.8(20.3)$ \\
Fasting glucose (mg/dL) & $102.6(12.7)$ & $91.5(9.5)$ \\
HOMA-IR & $3.3(2.9)$ & $2.7(1.2)^{\star}$ \\
E-selectin (ng/mL) & $14.9(4.8)$ & $12.2(4.1)^{\star \star}$ \\
CIMT & $0.6(0.1)$ & $0.5(0.1)^{\star}$ \\
\hline
\end{tabular}

CIMT: carotid aretery intima-media thickness; HOMA: homeostatic model assessment. ${ }^{*} p<0.05$ and ${ }^{* *} p<0.01$; compared to patients.

Table 3. Correlation of E-selectin levels to demographic and clinical parameters in the overall study population

\begin{tabular}{lcc}
\hline \multirow{2}{*}{ Variables } & \multicolumn{2}{c}{ E-selectin levels } \\
\cline { 2 - 3 } & $\mathbf{r}$ & p value \\
\hline Age & 0.221 & 0.06 \\
BMI & 0.050 & 0.762 \\
Waist/Hip Ratio & 0.143 & 0.226 \\
Total cholesterol (mg/dL) & 0.408 & $<\mathbf{0 . 0 0 1}$ \\
Triglycerides (mg/dL) & 0.111 & 0.348 \\
HDL cholesterol (mg/dL) & 0.197 & 0.095 \\
LDL cholesterol (mg/dL) & 0.024 & 0.840 \\
hs-CRP & 0.751 & $<\mathbf{0 . 0 0 1}$ \\
Fasting glucose (mg/dL) & 0.204 & 0.083 \\
HOMA-IR & 0.575 & $<\mathbf{0 . 0 0 1}$ \\
Carotid-IMT & 0.762 & $<\mathbf{0 . 0 0 1}$ \\
\hline
\end{tabular}



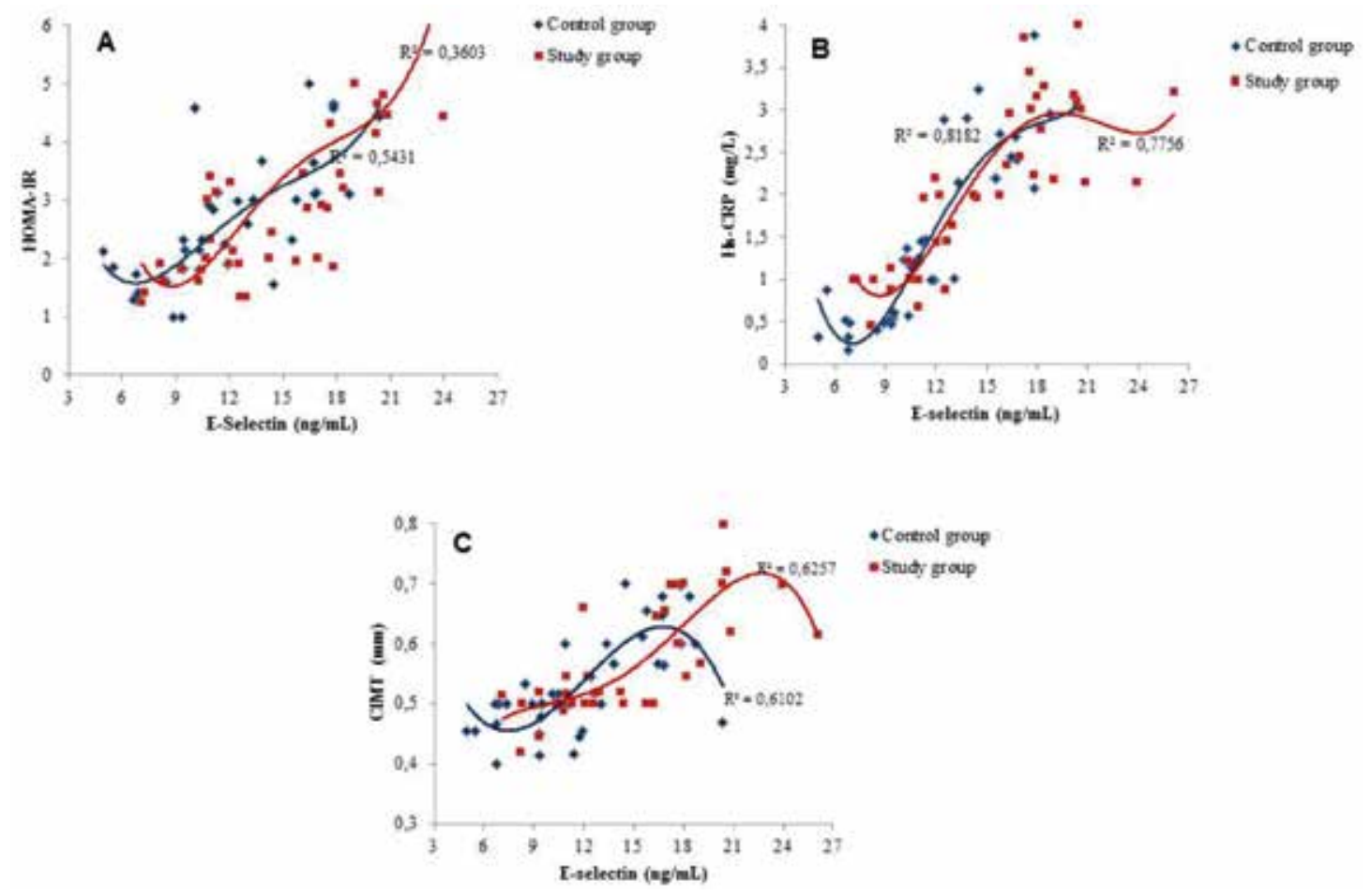

Figure 1. Correlations of E-selectin to HOMA-IR; HSCRP; and CIMT.

\section{Linear regression analysis for factors predicting E-selectin levels}

In linear regression analysis, after adjusting for age, BMI, waist/hip ratio, morning cortisol, HOMA-IR, TC, LDL-C, HDL-C and hsCRP; HOMA-IR $(\beta=$ $0.455, \mathrm{P}<0.05)$ and waist/hip ratio $(\beta=0.340, \mathrm{P}<$ $0.05)$ were the independent variables associated with E-selectin levels.

\section{Demographic and clinical characteristics of patients with respect to insulin resistance}

When NFA patients with insulin resistance (HOMA-IR $>2.5 \mathrm{n}=20$ ) were evaluated separately, it was noted that patients with insulin resistance had significantly higher mean (SD) values for CIMT $(0.6[0.1])$ and hsCRP (2.7 [0.9]) as compared to patients without insulin resistance $(0.5[0.1]$ and 1.4 [0.6], respectively; $\mathrm{p}$ $<0.05$ for each) as well as healthy controls $(0.5[0.1]$ and $1.5[1.1]$, respectively; $\mathrm{p}<0.05$ for each) (Table 4 ).

\section{DISCUSSION}

The novel finding of our study is that patients with NFA compared with cardiovascular risk factors-matched control group had significantly higher CIMT and E- selectin levels as a surrogate marker of premature atherosclerosis. At the same time, we demonstrated that, in patients with NFA, increase in insulin resistance could be related to an undetectable hypercortisolism. These findings support the hypothesis that incidentalomas, through clinically undetectable hypercortisolism, might be responsible for IR and, through the stimulation of compensatory hyperinsulinemia, might induce and sustain the vicious cycle responsible for its own tumor growth. Reincke and cols. (19) reported that in 13 patients with AI, insulin resistance was evident in all patients, and insulin-stimulated adrenal cortex cancer cell lines were observed in vitro. They suggested that AI could be a newly recognized manifestation of metabolic syndrome similar to insulin-mediated stimulation of ovary in the polycystic ovary syndrome.

Patients with clinically inactive adrenal adenomas as a group exhibit IR and a variety of metabolic disturbances and manifestations of the metabolic syndrome (20-23). In a multi-institutional study of 1,004 patients with AI, the prevalence of arterial hypertension, diabetes mellitus type 2 (DM type 2 ) or obesity were reported to be $41 \%, 10 \%$ and $28 \%$, respectively (2). Furthermore, a remarkably high prevalence of impaired glucose tolerance (IGT), or previously unknown DM type 2, increased visceral fat mass, and hyperinsulinaemia has 
been demonstrated among patients with NFA $(24,25)$. This insulin-resistant state is probably associated with subtle cortisol autonomy leading to an increased incidence of several cardiovascular risk factors.

Patients with AI exhibit elevated levels of D-dimers (24), interleukin-6 (IL-6), adiponectin, resistin, tumour necrosis factor (TNF)-alpha and monocyte chemoattractant protein 1 (MCP-1) (3). In the current literature there is a limited data regarding the endothelial dysfunction and early atherosclerosis in patients with adrenal incidentaloma $(26,27)$.

Notably, our findings seem to indicate a significant association between endothelial dysfunction ans early atherosclerosis given that serum E-selectin levels were significantly elevated in patients with NFA than controls along with significant correlation of serum E-selectin levels with hsCRP, HOMA-IR and CIMT.

Carotid IMT has been extensively used to estimate cardiovascular events in both healthy individuals and also in subjects with risk factors. The early increase in IMT reflects the ongoing adaptive/maladaptive process to elevated intravascular shear stress (28). Several anthropometric and metabolic findings such as age, elevated blood pressure, central obesity, hyperlipidemia, and IR have been shown as independent determinants of IMT in different populations (29-31). In a past study concerning CIMT in AI (26) it was demonstrated that in patients with non-functioning AI, a significant increase of CIMT was observed compared with BMI -unmatched subjects, while the increase was not statistically significant when compared to BMI matched controls. A linear correlation between morning cortisol and CIMT values were also reported in this study.
In the present study, we found significantly higher CIMT values in NFA patients as compared to age-, gender- and BMI-matched controls. However, CIMT values were not significantly correlated with morning cortisol and dexamethasone suppression test results. Moreover, E-selectin levels that indicate endothelial dysfunction were higher in these patients. The present study is the first in the literature to evaluate early atherosclerosis and endothelial dysfunction together in NFA patients. Furthermore, our findings revealed higher rate of insulin resistance in patients with NFA along with significantly higher levels for hsCRP and CIMT in NFA patients with concomitant insulin resistance compared to patients without insulin resistance. In the present study, increased cardiovascular risk, as evidenced by increased E-selectin levels and IMT values, in NFA patients might have resulted from IR due to a subclinical cortisol excess at cellular level rather than the direct effect of cortisol. In the light of these data, we found increased risk of early atherosclerosis and impaired endothelial function in patients with clinically silent adrenal incidentaloma.

Major limitation of the present study is the small sample size which limits the generalization of our findings based on a small cohort to the overall population of NAF patients. Additionally, the assessment of endothelial dysfunction and atherosclerosis were limited to measurement of soluble E-selectin levels and CIMT measurement, respectively. Hence, our findings related to association of circulating E-selectin levels and insulin resistance to early atherosclerosis should be justified by larger scale studies with more comprehensive analysis of endothelial dysfunction and early atherosclerosis markers.

Table 4. Demographic and clinical characteristics of patients with respect to insulin resistance

\begin{tabular}{|c|c|c|c|}
\hline & \multicolumn{2}{|c|}{ Nonfunctional adrenal incidentaloma $(n=40)$} & \multirow{3}{*}{ Control $(n=35)$} \\
\hline & HOMA-IR > $2.5(n=20)$ & HOMA-IR $<2.5(n=20)$ & \\
\hline \multicolumn{3}{|c|}{ Mean (SD) } & \\
\hline Age (years & $55.8(10.5)$ & $55.5(11.1)$ & $51.5(8.1)$ \\
\hline $\mathrm{BMl}\left(\mathrm{kg} / \mathrm{m}^{2}\right)$ & $28.5(1.9)$ & $27.7(2.2)$ & $28.0(1.9)$ \\
\hline Waist/hip ratio & $0.8(0.1)$ & $0.8(0.0)$ & $0.9(0.1)$ \\
\hline Total cholesterol (mg/dL) & $189.9(35.4)$ & $180.8(23.5)$ & $191.3(29.8)$ \\
\hline Triglycerides (mg/dL) & $124.4(52.9)$ & $134.2(51.6)$ & $136.0(52.3)$ \\
\hline HDL cholesterol (mg/dL) & $62.7(29.3)$ & $52.4(20.4)$ & $48.2(10.1)$ \\
\hline LDL cholesterol (mg/dL) & $97.9(38.9)$ & $101.3(21.0)$ & $112.8(20.3)$ \\
\hline Carotid-IMT & $0.6(0.1)$ & $0.5(0.1)^{\star}$ & $0.5(0.1)^{*}$ \\
\hline hsCRP & $2.7(0.9)$ & $1.4(0.6)^{*}$ & $1.5(1.1)^{*}$ \\
\hline
\end{tabular}

${ }^{*} p<0.05$ compared to NFA patients with HOMA-IR $>2.5$. 


\section{CONCLUSION}

In conclusion, based on significantly higher values for E-selectin, CIMT and HOMA-IR in patients with NFA than controls along with significant correlation of E-selectin levels to CIMT, HOMA-IR and hs-CRP, our findings seems to indicate an increased risk of early atherosclerosis and impaired endothelial function in patients with clinically silent adrenal incidentaloma. Significantly higher values for CIMT and hs-CRP in NFA patients with insulin resistance when compared to patients without insulin resistance and control subjects emphasize the accelerating effect of insulin resistance in development of early atherosclerosis in patients with NFA. There is a need for long-term, prospective follow-up studies investigating the effect of surgical treatment of adrenal incidentalomas on cardiac mortality through the regulation of increased cardiovascular risk and endothelial function.

Acknowledgement: none.

Disclosure: no potential conflict of interest relevant to this article was reported.

\section{REFERENCES}

1. Mansmann G, Lau J, Balk E, Rothberg M, MiyachiY, Bornstein SR. The clinically inapparent adrenal mass: update in diagnosis and management. Endocr Rev. 2004;25(2):309-40.

2. Mantero F, Terzolo M, Arnaldi G, Osella G, Masini AM, Alì A, et al. A survey on adrenal incidentaloma in Italy. Study Group on AdrenalTumors of the Italian Society of Endocrinology. J Clin Endocrinol Metab. 2000;85(2):637-44.

3. Ermetici F, Malavazos AE, Corbetta S, Morricone L, Dall'Asta C, Corsi MM, et al. Adipokine levels and cardiovascular risk in patients with adrenal incidentaloma. Metabolism. 2007;56(5):686-92.

4. Ambrosi B, Peverelli S, Passini E, Re T, Ferrario R, Colombo P, et al. Abnormalities of endocrine function in patients with clinically "silent" adrenal masses. Eur J Endocrinol. 1995;132(4):422-8.

5. Chiodini I, Morelli V, Salcuni AS, Eller-Vainicher C, Torlontano $M$, Coletti F, et al. Beneficial metabolic effects of prompt surgical treatment in patients with an adrenal incidentaloma causing biochemical hypercortisolism. J Clin Endocrinol Metab. 2010;95(6):2736-45.

6. Rossi R, Tauchmanova L, Luciano A, Di Martino M, Battista C, Del Viscovo $L$, et al. Subclinical Cushing's syndrome in patients with adrenal incidentaloma: clinical and biochemical features. J Clin Endocrinol Metab. 2000;85(4):1440-8.

7. Tauchmanovà $L$, Rossi $R$, Biondi $B$, Pulcrano $M$, Nuzzo V, Palmieri EA, et al. Patients with subclinical Cushing's syndrome due to adrenal adenoma have increased cardiovascular risk. J Clin Endocrinol Metab. 2002;87(11):4872-8.

8. Reincke M, Beuschlein F, Slawik M, Borm K. Molecular adrenocortical tumorigenesis. Eur J Clin Invest. 2000;30:63-8.

9. Jang Y, Lincoff AM, Plow EF, Topol EJ. Cell adhesion molecules in coronary artery disease. J Am Coll Cardiol. 1994;24(7):1591-601.
10. Vaidya D, Szklo M, Cushman M, Holvoet P, Polak J, Bahrami H, et al. Association of endothelial and oxidative stress with metabolic syndrome and subclinical atherosclerosis: multi-ethnic study of atherosclerosis. Eur J Clin Nutr. 2011;65(7):818-25.

11. Porta B, Baldassarre D, Camera $M$, Amato $M$, Arquati M, Brusoni B, et al.; MIAMI Study Group. E-selectin and TFPI are associated with carotid intima-media thickness in stable IHD patients: the baseline findings of the MIAMI study. Nutr Metab Cardiovasc Dis. 2008;18(4):320-8.

12. Lu HH, Sheng ZQ, Wang $Y$, Zhang L. Levels of soluble adhesion molecules in patients with various clinical presentations of coronary atherosclerosis. Chin Med J (Engl). 2010;123(21):3123-6.

13. Hwang SJ, Ballantyne CM, Sharrett AR, Smith LC, Davis CE, Gotto AM Jr, et al. Circulating adhesion molecules VCAM-1, ICAM-1, and E-selectin in carotid atherosclerosis and incident coronary heart disease cases: the Atherosclerosis Risk In Communities (ARIC) study. Circulation. 1997;96(12):4219-25.

14. Sakurai S, Kitamura A, Cui R, Yamagishi K, Tanigawa T, Iso H. Relationships of soluble E-selectin and high-sensitivity $\mathrm{C}$-reactive protein with carotid atherosclerosis in Japanese men. J AtherosclerThromb. 2009;16(4):339-45.

15. Gotoh R, Suzuki J, Kosuge H, Kakuta T, Sakamoto S, Yoshida M, et al. E-selectin blockade decreases adventitial inflammation and attenuates intimal hyperplasia in rat carotid arteries after balloon injury. ArteriosclerThromb Vasc Biol. 2004;24(11):2063-8.

16. Terzolo M, Osella G, Alì A, Borretta G, Cesario F, Paccotti P, et al. Subclinical Cushing's syndrome in adrenal incidentaloma. Clin Endocrinol (Oxf). 1998;48(1):89-97.

17. Nieman LK, Biller BM, Findling JW, Newell-Price J, Savage MO, Stewart PM, et al. The diagnosis of Cushing's syndrome: an Endocrine Society Clinical Practice Guideline. J Clin Endocrinol Metab. 2008;93(5):1526-40.

18. Morelli V, Masserini B, Salcuni AS, Eller-Vainicher C, Savoca C, Viti $R$, et al. Subclinical hypercortisolism: correlation between biochemical diagnostic criteria and clinical aspects. Clin Endocrinol (Oxf). 2010;73(2):161-6.

19. Reincke M, Fassnacht M, Väth S, Mora P, Allolio B. Adrenal incidentalomas: a manifestation of the metabolic syndrome? Endocr Res. 1996;22(4):757-61.

20. Grumbach MM, Biller BM, Braunstein GD, Campbell KK, Carney JA, Godley PA, et al. Management of the clinically inapparent adrenal mass ("incidentalomas"). Ann Intern Med. 2003;138(5):424-9.

21. Kloos RT, Gross MD, Francis IR, Korobkin M, Shapiro B. Incidentally discovered adrenal masses. Endocr Rev. 1995;16(4):460-84.

22. Terzolo M, Pia A, Alì A, Osella G, Reimondo G, Bovio S, et al. Adrenal incidentaloma: a new cause of the metabolic syndrome? J Clin Endocrinol Metab. 2002;87(3):998-1003.

23. Terzolo M, Bovio S, Reimondo G, Pia A, Osella G, Borretta G, et al. Subclinical Cushing's syndrome in adrenal incidentalomas. Endocrinol Metab Clin North Am. 2005;34(2):423-39, x.

24. Fernández-Real JM, Engel WR, Simó R, Salinas I, Webb SM. Study of glucose tolerance in consecutive patients harbouring incidental adrenal tumours. Study Group of Incidental Adrenal Adenoma. Clin Endocrinol (Oxf). 1998;49(1):53-61.

25. Garrapa GG, Pantanetti P, Arnaldi G, Mantero F, Faloia E. Body composition and metabolic features in women with adrenal incidentaloma or Cushing's syndrome. J Clin Endocrinol Metab. 2001;86(11):5301-6.

26. Yener S, Comlekci A, Akinci B, Secil M, Demir T, Ertilav $S$, et al. Non-functioning adrenal incidentalomas are associated with elevated D-dimer levels. J Endocrinol Invest. 2009;32(4):338-43.

27. ErbilY, Ozbey N, Barbaros U, Unalp HR, Salmaslioglu A, Ozarmagan S. Cardiovascular risk in patients with nonfunctional adre- 
nal incidentaloma: myth or reality? World J Surg. 2009;33(10): 2099-105.

28. Lane HA, Smith JC, Davies JS. Noninvasive assessment of preclinical atherosclerosis. Vasc Health Risk Manag. 2006;2(1): 19-30.

29. de Groot E, van Leuven SI, Duivenvoorden R, Meuwese MC, Ak$\operatorname{dim}$ F, Bots ML, et al. Measurement of carotid intima-media thickness to assess progression and regression of atherosclerosis. Nat Clin Pract Cardiovasc Med. 2008;5(5):280-8.
30. Juonala $M$, Kähönen $M$, Laitinen T, Hutri-Kähönen $N$, Jokinen $E$, Taittonen $\mathrm{L}$, et al. Effect of age and sex on carotid intima-media thickness, elasticity and brachial endothelial function in healthy adults: the cardiovascular risk inYoung Finns Study. Eur Heart J. 2008;29(9):1198-206.

31. Sandrock M, Hansel J, Schulze J, Schmitz D, Niess A, Burkhardt $H$, et al. Sequentially based analysis versus image based analysis of Intima Media Thickness in common carotid arteries studies do major IMT studies underestimate the true relations for cardioand cerebrovascular risk? Cardiovasc Ultrasound. 2008;6:32. 